\title{
A COST-EFFECTIVENESS ANALYSIS OF rhDNase IN CHILDREN WITH CYSTIC FIBROSIS
}

\author{
Richard Grieve \\ London School of Hygiene and Tropical Medicine
}

Simon Thompson

MRC Biostatistics Unit

Charles Normand

London School of Hygiene and Tropical Medicine

\section{Ranjan Suri \\ Andrew Bush}

Royal Brompton and Harefield NHS Trust

Colin Wallis

Great Ormond Street Hospital for Children NHS Trust

\begin{abstract}
Objectives: This study compared the relative cost-effectiveness of daily recombinant human deoxyribonuclease (rhDNase), with alternate day rhDNase and hypertonic saline (HS) for treating children with cystic fibrosis (CF).

Methods: A randomized controlled trial with a crossover design allocated $40 \mathrm{CF}$ children consecutively to 12 weeks of daily rhDNase, alternate day rhDNase, or HS. The primary outcome measure was forced expiratory volume in 1 second $\left(\mathrm{FEV}_{1}\right)$, a measure of lung function. All health resource use was prospectively documented for each patient and multiplied by unit costs to give a total health service cost for each 12-week treatment period. The nonparametric bootstrap method was used to present costeffectiveness acceptability curves and net benefit statistics for each treatment comparison, for various hypothetical levels of the decision maker's ceiling ratio.

Results: Compared with HS, there was a $14 \%$ improvement in $\mathrm{FEV}_{1}$ for daily rhDNase $(95 \% \mathrm{Cl}, 5 \%$ to $23 \%)$, and a $12 \%$ improvement $(95 \% \mathrm{Cl}, 2 \%$ to $22 \%)$ for alternate day rhDNase. For a ceiling ratio of $£ 200$ per $1 \%$ gain in $\mathrm{FEV}_{1}$, the mean net benefits of daily and alternate day rhDNase compared with HS were $£ 1,158(95 \% \mathrm{Cl},-£ 621$ to 2,842$)$ and $£ 1,188(95 \% \mathrm{Cl},-847$ to 3,343$)$, respectively; the mean net benefit of daily compared with alternate day rhDNase was $-£ 30(95 \% \mathrm{Cl},-£ 2,091$ to 1,576$)$.

Conclusions: If decision makers are prepared to pay $£ 200$ for a $1 \%$ gain in $\mathrm{FEV}_{1}$ over a 12 -week period, then on average either rhDNase strategy is cost-effective.
\end{abstract}

The authors are grateful for the contribution of Marcus Flather, Belinda Lees, and Pauline Dooley from the Clinical Trials and Evaluations Unit, the Royal Brompton Hospital for their considerable contribution to the original study and their assistance with randomization, database design, and management. This study was funded by the NHS Health Technology Assessment Programme and carried out at the Royal Brompton and Harefield NHS Trust, Great Ormond Street Hospital for Children NHS Trust, and the Institute of Child Health.

There were no conflicts of interest. 
Keywords: Costs, Cost analysis, Cystic fibrosis

Cystic fibrosis (CF) is the most common autosomal recessive disorder of Caucasians. New therapies have improved life expectancy in $\mathrm{CF}$, but have also increased healthcare costs. Clinical trials of recombinant human deoxyribonuclease (rhDNase) have shown improvements in lung function (19). However, rhDNase is an expensive therapy, costing around $£ 7,500$ per patient per year, and not all patients benefit from it (8). This suggests that there is a need for economic evaluations that give information on the relative cost-effectiveness of rhDNase compared with other treatment strategies for CF, such as hypertonic saline (HS).

Previous health technology assessments for CF have applied cost-consequence analysis to compare treatment strategies. Oster et al. (15) used data from a U.S. clinical trial that compared the effectiveness of rhDNase with placebo in adults with CF (8). However, this study excluded the cost of rhDNase and only assessed respiratory tract infection-related health costs. The study suggested that rhDNase (administered once or twice daily) improved patients' lung function and reduced hospitalizations, which could potentially offset around $25 \%$ of the drug's cost. Menzin et al. (12) used data from the same U.S. trial to compare the costs of rhDNase with placebo in four different European countries. The analysis used expert opinion to adapt the resource use observed in the trial to a European context, and concluded that rhDNase could reduce health service costs by between US $\$ 700$ and $\$ 1,000$ over 6 months. The validity of the latter study was limited by the extent to which data could be transferred between the United States and Europe.

A U.K. study has recently compared the effectiveness and costs of treating children with $\mathrm{CF}$ with daily rhDNase $(2.5 \mathrm{mg})$, alternate day rhDNase $(2.5 \mathrm{mg})$ and HS (21). The study was based on a randomized controlled trial with a crossover design, with 40 patients receiving each treatment for 12 weeks, with a 2-week washout period between treatments (22). The primary outcome measure was the patients' lung function measured by forced expiratory volume in 1 second $\left(\mathrm{FEV}_{1}\right)$. Comparing mean $\mathrm{FEV}_{1}$ between the treatments, the trial reported an $8 \%(95 \% \mathrm{CI}, 2 \%$ to $14 \%, p=.01)$ advantage for daily rhDNase over HS, but none for daily compared with alternate day rhDNase $(2 \%, 95 \% \mathrm{CI},-4 \%$ to $9 \%$, $p=.55)(22)$.

The aim of this paper is to extend this analysis and estimate the relative cost-effectiveness of daily rhDNase, alternate day rhDNase, and HS for children with CF over a 12-week period. This requires costs and effects to be reported using a summary measure such as the incremental cost-effectiveness ratio (ICER). However, difficulties surrounding the measurement and interpretation of statistical uncertainty with ICERs have been well documented $(2 ; 4 ; 14 ; 16)$. To avoid these problems, alternative measures of cost-effectiveness, including the cost-effectiveness acceptability curve (CEAC) and net benefit statistic (NB), have been developed $(20 ; 23)$. This paper illustrates the use of these alternative techniques using data from the U.K. cross-over trial described above.

\section{METHODS}

A cost-consequence analysis of the respective treatment strategies was specified in the original study protocol, and the methodology has been detailed elsewhere (21). To summarize, all healthcare resource use was measured for every patient included in the study over each treatment period. The resource use included hospital contacts (inpatient, outpatient, and day case), radiological investigations, blood tests, drugs, and the use of community services (including community nurse, physiotherapist, and general practitioner). Data were 
recorded from the patients' hospital notes, discharge letters, and by contacting the supervising physicians.

Unit costs of health services were collected at the two postgraduate hospitals where patients were recruited and from a local district general hospital. Drug costs were taken from the British National Formulary (BNF) (5), and community care costs from Netten et al. (13). All costs were adjusted to 1999-2000 prices using the hospital and community health services price index (9). Total costs for each treatment period were calculated by multiplying each patient's resource use by the appropriate unit cost. In the baseline analysis, the unit costs were from the specific study hospitals and the drug costs taken from the BNF.

The effectiveness of each of the treatment strategies was measured using the primary outcome measure from the trial $\left(\mathrm{FEV}_{1}\right)$, a measure of patients' lung function that is associated with mortality $(10 ; 11)$, and has been recommended for use in studies evaluating new treatments for CF (17). This measure was chosen in preference to measures of healthrelated quality of life (HRQoL), which would have been unlikely to be sensitive to change in treatment regimen over a 12-week period.

\section{Statistical and Sensitivity Analysis}

The aim of the analysis was to compare the relative cost-effectiveness of the three different strategies, so that the 40 patients who had received each of the treatments were included. This approach differed from the original trial analysis in which two separate pairwise comparisons, of daily rhDNase versus alternate day rhDNase $(n=43)$ and of HS versus daily rhDNase $(n=40)$, were undertaken. All statistical analyses are based on comparisons between treatments as assessed from within-patient differences, since the trial used a crossover design.

For each treatment period, the change in effectiveness was calculated by taking the natural logarithm of the end of treatment $\mathrm{FEV}_{1}, \mathrm{y}_{\mathrm{D}}, \mathrm{y}_{\mathrm{A}}, \mathrm{y}_{\mathrm{S}}$, and beginning of treatment $\mathrm{FEV}_{1}$ $\mathrm{x}_{\mathrm{D}}, \mathrm{x}_{\mathrm{A}}, \mathrm{x}_{\mathrm{S}}$ for daily rhDNase, alternate day rhDNase, and HS, respectively. The difference in $\log \mathrm{FEV}_{1}$ (e.g., $\mathrm{y}_{\mathrm{D}}-\mathrm{x}_{\mathrm{D}}$ ) was calculated for each treatment period and compared between treatments. For example, the incremental effectiveness of daily versus alternate day rhDNase, was $E_{D-A}=\left(y_{D}-x_{D}\right)-\left(y_{A}-x_{A}\right)$. This method of adjusting for the baseline differed from the original trial analysis, which used analysis of covariance. The incremental effectiveness was calculated on a log scale, which enabled the results to be interpreted in terms of percentage differences in $\mathrm{FEV}_{1}$

For each treatment comparison, the incremental cost was calculated as the difference in total costs and refers to a 12-week period. The mean incremental cost was reported with 95\% confidence intervals (CI) calculated using the nonparametric bootstrap (bias corrected method) (7). For each treatment comparison, the mean ICER was calculated by dividing the mean incremental cost by the mean incremental effectiveness, and corresponded to the additional average cost for a $1 \%$ improvement in $\mathrm{FEV}_{1}$.

The nonparametric bootstrapping approach was used to plot the incremental costs and effects on the cost-effectiveness plane (1), using 2,000 samples. The ceiling ratio $\left(\mathrm{R}_{c}\right)$ is defined as the amount that the healthcare decision maker is willing to pay (2). The CEAC shows the probability that the intervention is cost-effective for various values of $R_{\mathrm{c}}(2)$. The CEAC was derived by plotting the proportion of the bootstrap samples that may be regarded as cost-effective when the ceiling ratio was varied from $£ 0$ to $£ 400$ per $1 \%$ improvement in $\mathrm{FEV}_{1}$.

The net benefits approach $(\mathrm{NB})$ requires either the difference in costs or effects to be rescaled using the ceiling ratio $\left(R_{c}\right)$. Net benefits on the cost scale are defined as:

$$
N B=R_{c} \cdot \Delta \bar{E}-\Delta \bar{C}
$$


Net benefits were calculated for each bootstrap sample for a range of ceiling ratios from $£ 100$ to $£ 400$ per $1 \%$ increase in $\mathrm{FEV}_{1}$. Mean net benefits were reported with $95 \%$ bootstrap confidence intervals calculated using the bias-corrected method (7).

In the sensitivity analysis, the price of rhDNase was reduced from the BNF price by $10 \%-30 \%$ to assist with the generalizability of the results (3), since in practice healthcare providers may purchase rhDNase at a lower price. Similarly, the effect of changing the cost per hospital day was assessed to examine the impact of cost variation between providers.

\section{RESULTS}

A total of 47 children were recruited to the study. The mean age was 12.6 years (range from 7 to 17) and $83 \%$ were taking rhDNase at enrollment. Seven patients withdrew from one or all of the treatment periods and are excluded from the analysis (22). The mean resource use for each of the treatment periods was similar (Table 1), and the main reason for the differences in total cost was the higher unit cost of rhDNase ( $£ 20.39$ per day) compared with HS ( $£ 0.38$ per day). Compared with HS, there was a $14 \%$ improvement in $\mathrm{FEV}_{1}$ for daily rhDNase (95\% CI, $5 \%$ to $23 \%$ ) and a $12 \%$ improvement (95\% CI, $2 \%$ to $22 \%$ ) for alternate day rhDNase. There was no significant advantage for daily compared with alternate day rhDNase (2\% improvement in $\mathrm{FEV}_{1}$ with $95 \% \mathrm{CI},-6 \%$ to $12 \%$ ) (Table 2).

The bootstrap samples plotted on the cost-effectiveness plane for each of the comparisons show the uncertainty surrounding the mean estimate of cost-effectiveness reported

Table 1. Mean (SD) Resource Use, Total Costs, and Clinical Outcomes in Three Treatment Groups over 12 Weeks

\begin{tabular}{lccc}
\hline & HS & Daily rhDNase & Alternate day rhDNase \\
\hline Hospital admissions & $0.53(0.75)$ & $0.63(0.87)$ & $0.80(1.07)$ \\
Total inpatient days (no. days) & $5.13(8.84)$ & $4.73(7.73)$ & $5.65(7.70)$ \\
Outpatient visits (no. visits) & $1.23(1.10)$ & $0.93(1.07)$ & $0.83(0.81)$ \\
GP contacts (no. contacts) & $0.25(0.49)$ & $0.30(0.61)$ & $0.18(0.38)$ \\
Nurse contacts (no. contacts) & $2.70(10.12)$ & $1.75(6.65)$ & $2.38(7.91)$ \\
Total cost $(\mathfrak{)})$ & $4,285(3,903)$ & $5,694(3,377)$ & $5,230(3,737)$ \\
Effectiveness $\left(\% \text { change in } \mathrm{FEV}_{1}\right)^{\mathrm{a}}$ & $0(27)$ & $14(27)$ & $12(19)$ \\
\hline
\end{tabular}

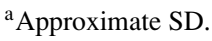

Table 2. Mean Incremental Cost, Incremental Effectiveness, and Net Benefit over 12 Weeks $(95 \% \mathrm{Cl})$

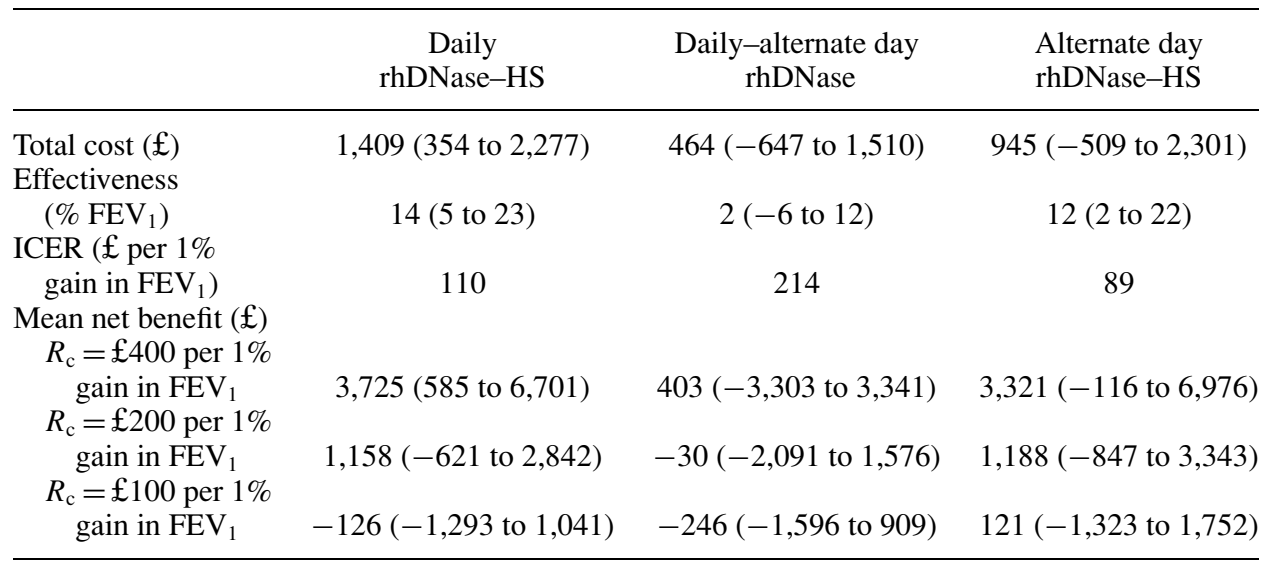


by the ICER (Figure 1A-C). The problem of interpreting negative ratios is illustrated in Figure 1B, where bootstrap samples fall in all four quadrants. Therefore an ICER of $-£ 200$ per $1 \%$ gain in $\mathrm{FEV}_{1}$ might represent improved outcomes and lower costs for daily compared with alternate day rhDNase, or worse outcomes and higher costs. This means that a meaningful ordering of the ratios, which is required to make confidence intervals around the ICER interpretable, is impossible.

Figure 2 shows the CEAC for each of the three comparisons. If the decision maker had a ceiling ratio of $£ 200$ per $1 \%$ gain in $\mathrm{FEV}_{1}$, the probability of daily or alternate day rhDNase proving cost-effective, compared with HS, would be 0.91 and 0.88 . For the same ceiling ratio, the probability of daily rhDNase being cost-effective, compared with alternate day rhDNase, is 0.49 .

The mean ICER for each comparison corresponded closely to the ceiling ratio $\left(R_{\mathrm{c}}\right)$ when the probability of one intervention being cost-effective was 0.5 . The CEAC cut the

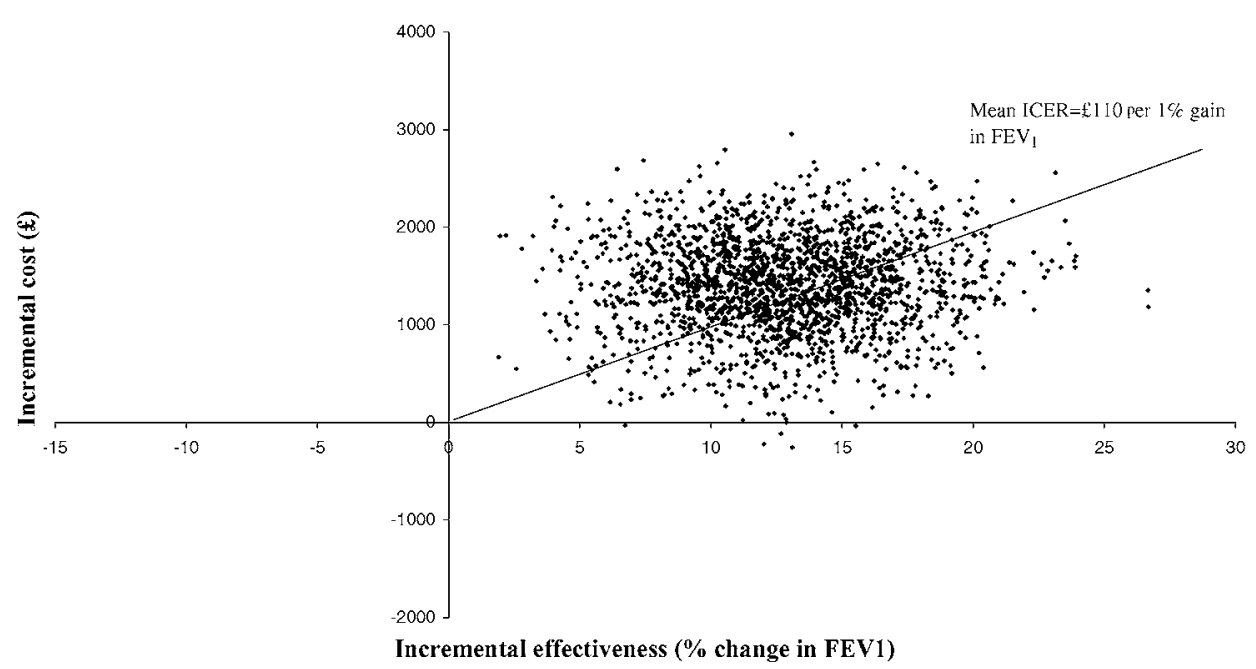

Figure 1A. Results on the cost-effectiveness plane of daily rhDNase-HS.

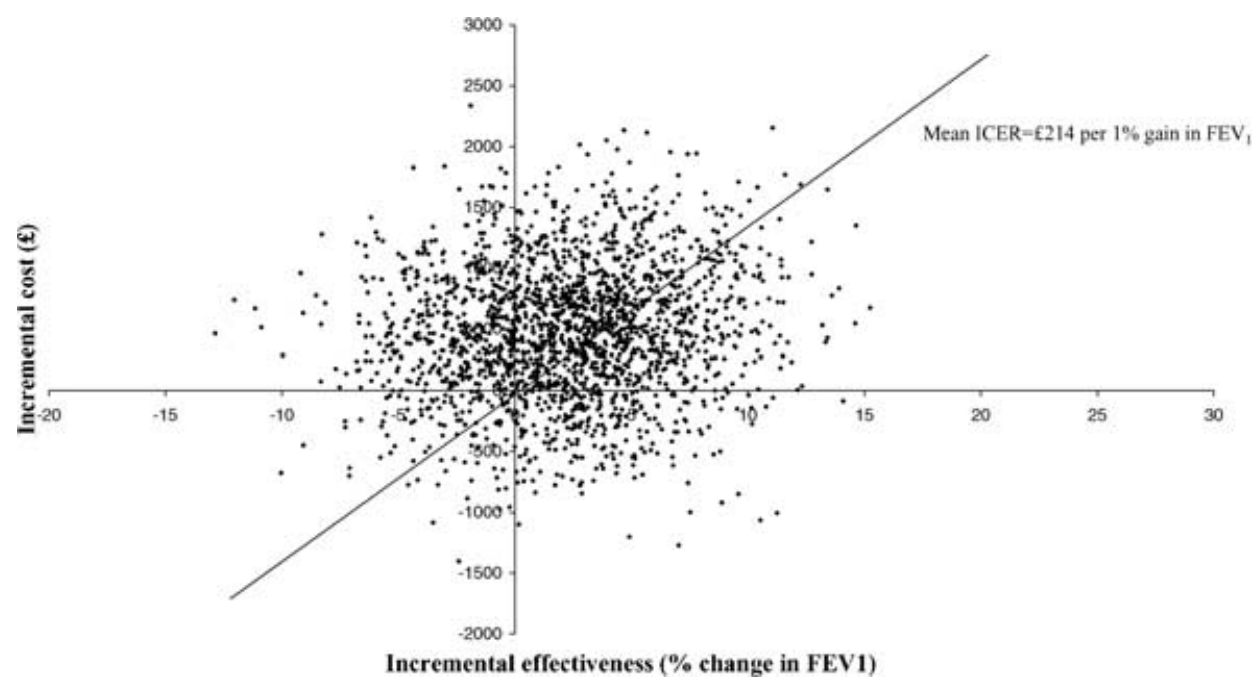

Figure 1B. Daily-alternate day rhDNase. 
Grieve et al.

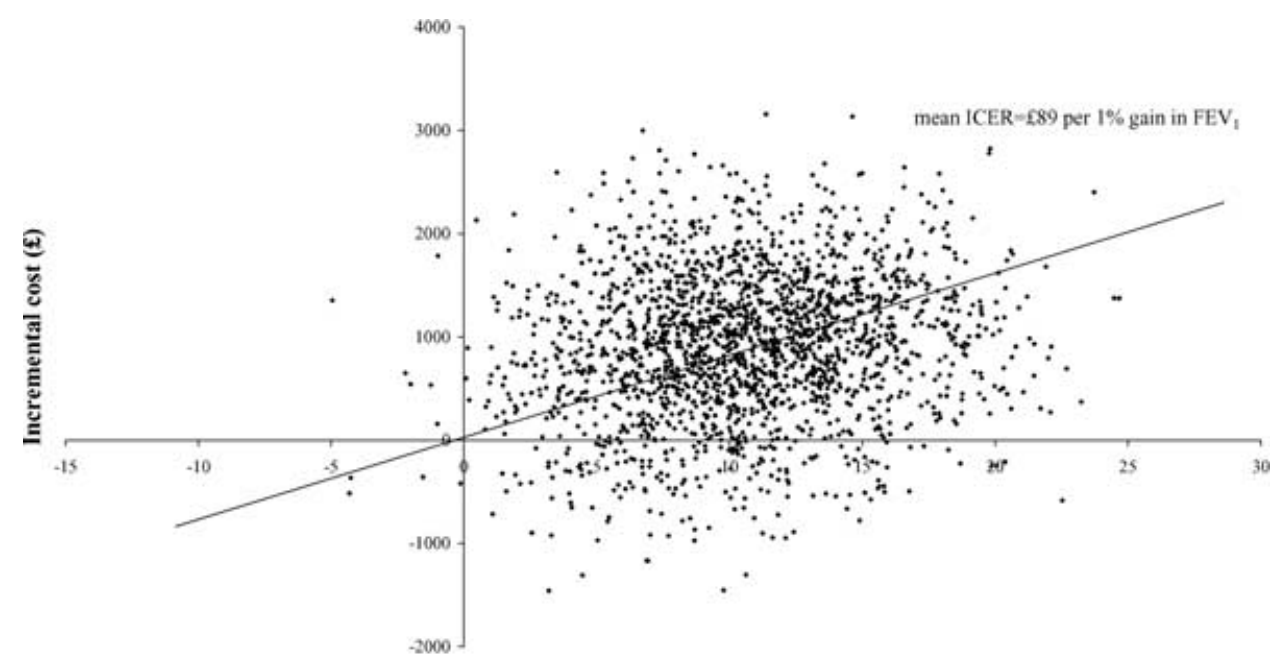

Incremental effectiveness ( $\%$ change in $\left.\mathrm{FEV}_{1}\right)$

Figure 1C. Alternate day rhDNase-HS.

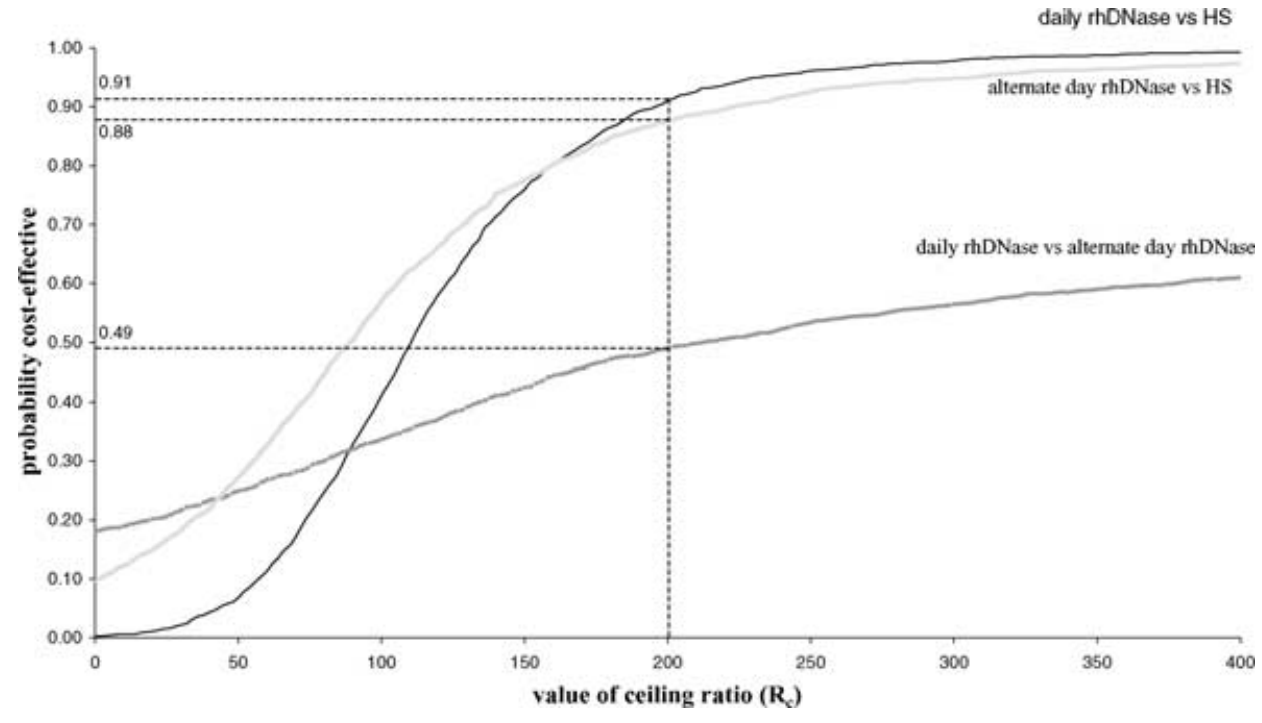

Figure 2. Cost-effectiveness acceptability curves.

vertical axis at the one-sided $p$ value for the cost difference (.001 for daily rhDNase vs HS), and asymptotes to 1 minus the one-sided $p$ value of the effectiveness difference (.999 for daily rhDNase vs HS).

Assuming that $R_{\mathrm{c}}=£ 200$ per $1 \%$ increase in $\mathrm{FEV}_{1}$, then the mean net benefits of daily and alternate day rhDNase compared with HS were $£ 1,158$ (95\% CI, -621 to 2,842) and $£ 1188$ (95\% CI, -847 to 3343), respectively (Table 2). At this ceiling ratio, the net benefit of daily compared with alternate day rhDNase was $-£ 30$ (95\% CI, $-2,091$ to 1,576$)$.

The sensitivity analysis did not find the results sensitive to the unit costs of hospital services, but changing the price of rhDNase was somewhat more important. For example, the probability of daily rhDNase compared with alternate day rhDNase being cost-effective, when $\mathrm{Rc}=£ 200$ per $1 \%$ gain in $\mathrm{FEV}_{1}$, rose from $49 \%$ to $59 \%$ as the price of rhDNase was reduced by $0 \%-30 \%$ (Figure 3 ). 


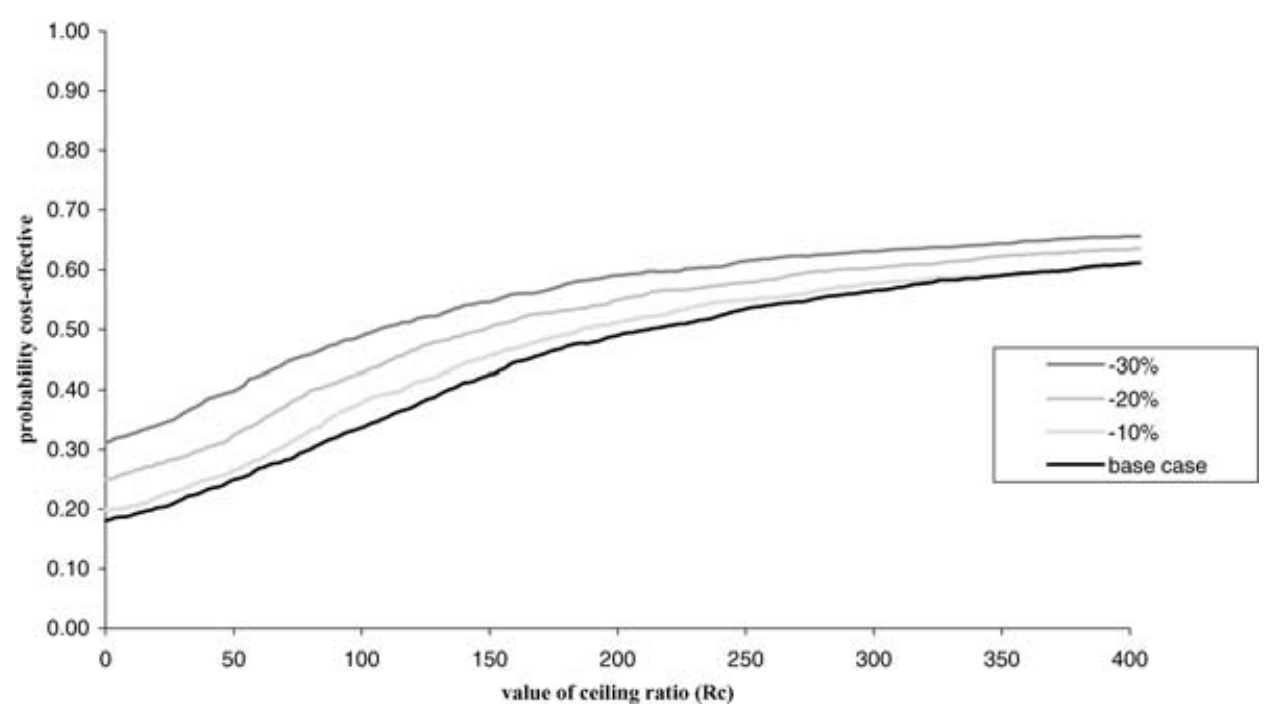

Figure 3. Sensitivity analysis: price of rhDNase on the CEAC of daily vs alternate day rhDNase.

\section{DISCUSSION}

This is the first full cost-effectiveness analysis of different treatment strategies for patients with CF. The main result was that rhDNase administered on an alternate or daily basis was more effective than HS. If decision makers are prepared to pay $£ 200$ for a $1 \%$ increase in $\mathrm{FEV}_{1}$ over a 12 -week period, the probability of daily or alternate day rhDNase proving cost-effective compared with HS is substantially greater than 50\%. At this ceiling ratio, the mean net benefits of daily rhDNase compared with HS are positive but with wide confidence intervals, illustrating the uncertainty that surrounds these results.

In the United Kingdom, children with CF who have moderate to severe lung disease are routinely prescribed daily rhDNase. This study suggests it may be more cost-effective if rhDNase is prescribed on an alternate-day basis. Unless decision makers are willing to pay over $£ 200$ per $1 \% \mathrm{FEV}_{1}$ gained, the probability of daily rhDNase proving more cost-effective than alternate day rhDNase is less than $50 \%$, and the mean net benefit is negative.

This study extends previous studies in this area by presenting detailed information on hospital and community health service resources and by including information on the cost of the interventions. The results show that while rhDNase improves outcomes, this is at an increased cost. In such circumstances, a full cost-effectiveness analysis was able to summarize the results using a single measure of cost-effectiveness. This work therefore extends the cost-consequence analyses previously published $(15 ; 21)$ and indicates clearly the trade-offs involved when choosing between competing interventions (6).

As this is the first study to present a full cost-effectiveness analysis for $\mathrm{CF}$, the possibility of comparing the results to other competing interventions is limited, and the decision makers' ceiling ratio is unknown. Further studies are needed to assess the cost-effectiveness of new high-cost interventions for CF (for example, nebulized TOBI Chiron, Emeryville, California, USA., [18]). In order to facilitate comparison between interventions, future studies need to use the same measures of cost-effectiveness.

One limitation of the study is the narrowness of the outcome measure used, which limits comparisons of cost-effectiveness to other studies evaluating therapies in $\mathrm{CF}$ or other 


\section{Grieve et al.}

lung diseases. The objective of the study was to provide decision makers with information on how best to allocate resources within this particular disease area, rather than across a range of healthcare interventions. To facilitate broader comparisons, a generic measure of outcome such as the quality-adjusted life-year (QALY) would have been needed. While the study did collect information on quality of life using a disease-specific measure, it was not possible to use this measure to derive QALY values.

This study is a rare example of a full economic evaluation alongside a crossover trial. This raised certain methodologic issues, in particular that all the results are based on paired differences within patients, which increases statistical efficiency. The method used to measure outcomes in the economic evaluation compared the between-treatment differences in outcome by subtracting the start of treatment $\mathrm{FEV}_{1}$ from the end of treatment $\mathrm{FEV}_{1}$ on a logged scale. This method adjusted for baseline values and provided results that could be used in the bootstrapping procedure required for the cost-effectiveness analysis. In the trial, analysis of covariance was used to provide baseline-adjusted outcome measures, but could not so easily be used as a basis for a cost-effectiveness analysis. The different methods produced somewhat different estimates of incremental effectiveness.

While this study reported measures of uncertainty around the cost-effectiveness measures based on the resource use and outcomes data observed in the study, other uncertainties exist that warrant further investigation. In particular, the examination of the impact of varying unit costs has been limited to deterministic sensitivity analysis. Further work will examine the extent to which incorporating statistical measures of uncertainty in unit costs may change the estimation of the magnitude of uncertainty surrounding the cost-effectiveness results.

\section{POLICY IMPLICATIONS}

If decision makers are prepared to pay $£ 200$ for a $1 \%$ gain in $\mathrm{FEV}_{1}$ (or $£ 2,000$ for a $10 \%$ gain) over a 12-week period, then either rhDNase strategy on average has positive net benefits compared with HS and should be adopted. This study suggests that providing rhDNase on an alternate-day basis may be the more cost-effective alternative. This evaluation did not find that daily rhDNase improves patient's lung function compared with alternate day rhDNase, and the total health service cost of alternate day rhDNase was on average about $£ 500$ lower over 12 weeks. Assuming that the pattern of health service use was maintained over a year, moving to alternate day rhDNase could lead to a reduction in annual health service costs of about $£ 2,000$ per patient.

This paper used appropriate measures of cost-effectiveness, the net benefit statistic, and cost-effectiveness acceptability curve in the context of a crossover trial. The use of these measures provided a further illustration of the uncertainty that surrounds the results of cost-effectiveness analyses. In this study, although alternate day rhDNase was associated with lower average total costs and similar outcomes to daily rhDNase, the confidence intervals around the average net benefit spanned zero for various levels of the ceiling ratio. This suggests that to establish that alternate-day rhDNase is more cost-effective than daily rhDNase, a larger study would be required.

\section{REFERENCES}

1. Black WC. The CE plane: A graphic representation of cost-effectiveness. Med Decis Making. 1990;10:212-214.

2. Briggs, AH, Fenn P. Confidence intervals or surfaces? Uncertainty on the cost-effectiveness plane. Health Econ. 1998;7:723-740.

3. Briggs AH, Gray AM. Handling uncertainty when performing economic evaluation of healthcare interventions. Health Technol Assess. 1999;3:1-134. 
4. Briggs AH, Mooney CZ, Wonderling DE. Constructing confidence intervals for cost-effectiveness ratios: An evaluation of parametric and non-parametric techniques using Monte Carlo simulation. Stat Med. 1999;18:3245-3262.

5. British Medical Association and the Royal Pharmaceutical Society of Great Britain. British national formulary. London: BMJ Books; 1999.

6. Drummond MF, O'Brien BJ, Stoddart GL, Torrance GW. Methods for the economic evaluation of health care programmes. 2nd ed. Oxford: Oxford University Press; 1997.

7. Efron B. Better bootstrap confidence intervals. J Am Stat Assoc. 1987;82:171-200.

8. Fuchs H, Borowiwitz DS, Christiansen DH, et al. Effect of aerosolized recombinant human DNase on exacerbations of respiratory symptoms and on pulmonary function in patients with cystic fibrosis. N Engl J Med. 1994;331:637-642.

9. Hospital and community health services (HCHS) pay and price index. Leeds; 1999.

10. Huang NN, Scidlar DV, Szatrowski TH, et al. Clinical features, survival rate and prognostic factors in young adults with cystic fibrosis. Am J Med 1987;82:871-877.

11. Kerem E, Reisen J, Carey M, et al. Predictions of mortality in patients with cystic fibrosis. $N$ Engl J Med 1992;326:1187-1191.

12. Menzin J, Oster G, Davies L, et al. A multinational economic evaluation of rhDNase in the treatment of cystic fibrosis. Int J Technol Assess Health Care. 1996;12:52-61.

13. Netten A, Dennett J, Knight J. Unit costs of health and social care 1999. Canterbury: Personal Social Services Research Unit, University of Kent; 1999.

14. O'Brien, BJ Drummond MF, Labelle RJ, Willan A. In search of power and significance: Issues in the design and analysis of stochastic cost-effectiveness studies in health care. Med Care. 1994;32:150-163.

15. Oster G, Huse DM, Lacey MJ, et al. Effects of recombinant human DNase therapy on healthcare use and costs in patients with cystic fibrosis. Ann Pharmacother. 1995;29:459-464.

16. Polsky D, Glick HA, Wilke R, Schulman K. Confidence intervals for cost-effectiveness ratios: A comparison of four methods. Health Econ. 1997;6:243-252.

17. Ramsey BW, Boat T. Outcome measures for clinical trials in cystic fibrosis. $J$ Pediatr. 1994;124:177-192.

18. Ramsey BW, Pepe MS, Quan JM, et al. Intermittent administration of inhaled tobraymycin in patients with cystic fibrosis: Cystic Fibrosis Inhaled Tobrramycin Study Group. $N$ Engl J Med. 1999;340:23-30.

19. Ranasinha C, Assoufi B, Shak S, et al. Efficacy and safety of short-term administration of aerosolised recombinant human DNase 1 in adults with stable stage cystic fibrosis. Lancet. 1993;342:199-202.

20. Stinnett AA, and Mullahy J. Net health benefits: A new framework for the analysis of uncertainty in cost-effectiveness analysis. Med Decis Making. 1998, S65-S80.

21. Suri R, Metcalfe C, Lees B, et al. A comparative study of hypertonic saline, daily and alternate day rhDNase in cystic fibrosis. Health Technol Assess. In press.

22. Suri R, Metcalfe C, Lees B, et al. A randomised comparative trial of hypertonic saline, alternate day and daily rhDNase in children with cystic fibrosis. Lancet. 2001;358:1316-1321.

23. Van Hout BA, Al MJ, Gordon GS, Rutten FFH. Costs, effects and C/E-ratios alongside a clinical trial. Health Econ. 1994;3:309-319. 